\title{
LOCOMOTIVE CRASHWORTHINESS DESIGN MODIFICATIONS STUDY
}

\author{
David Tyrell \\ Kristine Severson \\ Brian Marquis \\ Eloy Martinez \\ Volpe National Transportation Systems Center \\ US Department of Transportation \\ Cambridge, MA 02142 USA
}

\author{
Ron Mayville \\ Robert Rancatore \\ Richard Stringfellow \\ Randolph Hammond \\ Arthur D. Little, Inc. \\ Cambridge, MA 02140 USA
}

\author{
A. Benjamin Perlman \\ Department of Mechanical Engineering \\ Tufts University \\ Medford, MA 02155 USA
}

\begin{abstract}
A study has been conducted of locomotive crashworthiness in a range of collision scenarios to support the efforts of the Locomotive Crashworthiness Working Group of the Federal Railroad Administration's Railroad Safety Advisory Committee (RSAC) to develop locomotive crashworthiness requirements. The RSAC is a government/industry committee including all segments of the rail community, with the purpose of developing solutions to safety regulatory issues. This paper presents the results of a study of the crashworthiness of conventional and modified locomotive designs in five collision scenarios. The five collision scenarios studied are:

1. in-line collision of two locomotive-led trains with trailing locomotive overriding leading locomotive

2. in-line collision of two locomotive-led trains with one colliding locomotive overriding the other

3. locomotive grade crossing collision with highway vehicle hauling logs, with principal impact on locomotive window area

4. oblique collision, locomotive with intermodal trailer

5. oblique collision, locomotive with freight car
\end{abstract}

The locomotive design modifications studied include shelf couplers, $\mathrm{CN}$-design anti-climber, modified collision posts, increased window structure strength, and increased short hood strength.

Results of the study show that shelf couplers are not effective in preventing one locomotive from climbing another; the Canadian National $(\mathrm{CN})$ anti-climber design is not more effective than the conventional anti-climber design in preventing one locomotive from climbing another; increased window structure strength is effective in increasing locomotive crashworthiness in a collision with logs; increased short hood strength is effective in increasing locomotive crashworthiness in a collision with an intermodal trailer; and modifications to the locomotive front plate and plow designs will not influence the consequences of an oblique collision with a side-sill design covered hopper car.

\section{BACKGROUND AND INTRODUCTION}

In October of 1997, the Locomotive Crashworthiness Working Group of the RSAC formed an Engineering Task Force to develop and evaluate potential crashworthiness modifications to existing locomotive structural designs. The objective of this Task Force is to develop a base of technical information to allow the Working Group to recommend potential revisions and additions to existing Federal and industry locomotive crashworthiness standards. Members of this Task Force include representatives from the railroads, the locomotive suppliers, the unions, and the Federal Government. In July of 1998, an interim report on this study was presented to the Working Group, and in October of 1998, the final results were presented.

The purpose of this study is to develop modifications to current locomotive designs for improved crashworthiness and to determine their potential effectiveness. This paper summarizes the results of a study of locomotive crashworthiness performance in five collision scenarios. The steps taken as part of the study include:

- identification of the collision scenarios of concern

- development of potential locomotive crashworthiness design modifications

- $\quad$ adaptation of existing computer models to simulate the scenarios of concern

- comparison of model predictions with accident consequences

- $\quad$ evaluation and comparison of the effectiveness of current and modified locomotive designs in scenarios of concern

The scenarios were developed from a review conducted by the Task Force of information from approximately 40 accidents. From this review, five scenarios were selected, each with a corresponding accident. These collisions scenarios are intended to bound the range of collisions that a locomotive may be involved in and were used in the analyses of the crashworthiness performance of existing and modified locomotives.

The potential locomotive crashworthiness modifications were developed in consultation with the Working Group, particularly with the support of the locomotive suppliers. Meetings were held with both major North American suppliers of diesel-electric locomotives.

As part of previous studies of rail equipment crashworthiness (Mayville, et al, 1996 and Tyrell, et al, 1997) and other ongoing 
studies (Mayville, et al, 1999(1) and 1999(2)) an extensive library of train collision models has been developed. A number of concepts for preventing override have been developed as part of ongoing studies of passenger equipment crashworthiness. This effort made extensive use of existing models and explored the implementation of override protection mechanisms for freight locomotives. This effort focused on the locomotive operator, particularly in equipment operated in freight service.

\section{METHODOLOGY}

The objective of the analytic modeling of train collisions is to provide a framework for predicting the influence of structural modifications on locomotive crashworthiness. The principal information sought is the incremental increase in potentially survivable collision speed associated with design modifications. In order to develop this information, the models must provide mechanistic descriptions of train collisions, including the trajectories of the equipment during the collision, as well as the crush of the locomotive structures and the forces and decelerations imparted to occupants.

The information available from accidents includes observations on the equipment damage, including the structural components loaded during the collision, estimates of initial position and speed, and estimates of equipment final position. This information can be used to infer the sequence of events leading from the initial condition of the equipment to the post-collision condition, including the forces acting on the equipment during the collision. There is also information on occupant injury and fatality, which can be used to infer the forces and decelerations acting on the occupants. There are typically gaps and uncertainties in the information available from accidents, which leads to some uncertainties in the inferences.

During a train collision, the trajectories of the cars are dependent upon the linkage effects of the couplers. Because the cars are coupled, the train can buckle laterally, forming a zigzag pattern when viewed from above after the accident. Cars being coupled, in combination with the pitching motions of the cars and the deformations of their end structures can lead to one car climbing another. When climbing occurs, the relatively strong underframe of a car rides up and over the underframe of the adjacent car, often causing substantial damage to the relatively weak superstructure of the overridden car.

In a survivable train collision, the affected structures comprise a relatively small portion of the total mass of the equipment. For example, the short hood and collision posts - the elements crushed in the event of a head-on collision with override - comprise less than 2 percent of the entire weight of a high-horsepower locomotive. (For reference, in a survivable automobile head-on collision the weight of the elements crushed can be up to $1 / 3$ or more of the automobile weight -- the front bumper, fenders, frame rails, engine and transmission, and suspension elements.) In addition, the occupants are a small portion of the combined weight of the locomotive and occupants, and from a structural perspective, the occupants are substantially weaker than the locomotive.

Structural component crush behavior can be evaluated separately from train collision dynamics. The mass of the crushed structure is a small portion of the mass of the locomotive - in essence the crushed structure behaves like a non-linear spring. The occupant dynamics can be calculated separately from component crush and train collision dynamics.
Figure 1. illustrates the approach used in this study to simulate train collisions. The collisions are analyzed in two steps:

Step 1: Car Crush Behavior. Detailed dynamic, non-linear, large displacement finite-element models of the structures loaded in the five collision scenarios have been developed. These models approximate the loading conditions in the collision. A rigid impactor strikes the modeled structure in a fashion similar to the way the structure is hit in the collision scenario, and at similar impact speeds. The principal purpose of these models is to develop the force/crush behavior for different locomotive structure designs for use in developing the crush elements of the collision dynamics models. These models have been implemented in ABAQUS/Explicit (ABAQUS/Explicit User's Manual, 1998), and all include the influence of material failure.

Step 2: Train Collision Dynamics. Plane and Threedimensional lumped-mass collision dynamics models have been used to determine the trajectories of the locomotive and other equipment involved in four of the five collision scenarios. Impact elements have been used in these collision dynamics models, with the parameters for these elements taken from the results of the finite-element analyses of car crush behavior. The collision dynamics models have been used to evaluate the influence of structure design on intrusion into the operator's cab, and the deceleration of the locomotive during the collision. These models have been implemented in ADAMS (Bertorelli, N., et al, 1997).

While not included in this study, the occupant volume crush and decelerations developed from the collision dynamics models can be used to determine the response of the occupants during a train collision.

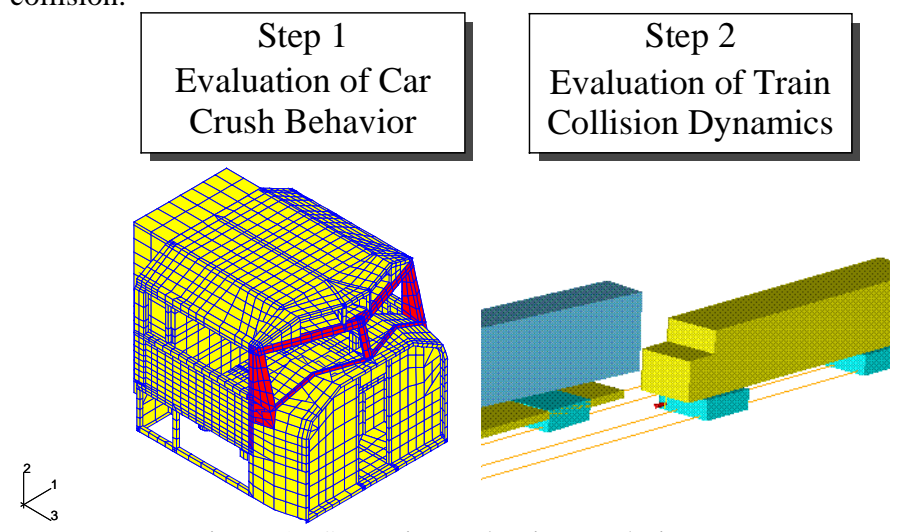

Figure 1. Scenario Evaluation Technique.

\section{COLLISION SCENARIOS OF CONCERN}

Five scenarios were chosen for evaluation: three head-on collision scenarios and two oblique collision scenarios. Each of these collision scenarios is associated with one or more accidents. Table 1 . lists the collision scenario, the collision mode (i.e., a description of the trajectory of the locomotive), the components considered for design modification, and the location and date of an accident that corresponds to the scenario. Data from these accidents were used for comparison with the analytic models and, where possible, for information on the crashworthiness performance of the baseline locomotive design. For Scenarios $3 \mathrm{a}$ and $3 \mathrm{~b}$, the model was compared with the accident that occurred in Phoenixville on August 23, 1996, but the grade crossing collision with logs impacting the window structure was used to evaluate the influences of changes in the window structure. 
Table 1. Collision Scenario, Collision Mode, and Accident Representative of Scenario.

\begin{tabular}{|c|c|c|c|c|}
\hline & $\begin{array}{l}\text { Collision } \\
\text { Scenario }\end{array}$ & $\begin{array}{l}\text { Collision } \\
\text { Mode }\end{array}$ & $\begin{array}{l}\text { Modified } \\
\text { Component }\end{array}$ & $\begin{array}{l}\text { Accident Location } \\
\text { and Date }\end{array}$ \\
\hline 1 & $\begin{array}{l}\text { Head-on } \\
\text { collision between } \\
\text { two freight trains }\end{array}$ & $\begin{array}{l}\text { Coupled } \\
\text { locomotive } \\
\text { override }\end{array}$ & $\begin{array}{l}\text { Anti- } \\
\text { climber } \\
\text { Shelf- } \\
\text { coupler }\end{array}$ & $\begin{array}{l}\text { Smithfield, WV, } \\
\text { August 20, } 1996\end{array}$ \\
\hline 2 & $\begin{array}{l}\text { Head-on } \\
\text { collision between } \\
\text { two freight trains }\end{array}$ & $\begin{array}{l}\text { Colliding } \\
\text { locomotive } \\
\text { override }\end{array}$ & $\begin{array}{l}\text { Collision } \\
\text { post }\end{array}$ & $\begin{array}{l}\text { West Eola, IL, } \\
\text { January } 201993\end{array}$ \\
\hline $3 a$ & $\begin{array}{l}\text { Overtaking } \\
\text { collision, } \\
\text { locomotive to } \\
\text { flat car }\end{array}$ & $\begin{array}{l}\text { Loading of } \\
\text { window } \\
\text { frame } \\
\text { structure } \\
\end{array}$ & $\begin{array}{l}\text { Window } \\
\text { frame } \\
\text { structure }\end{array}$ & $\begin{array}{l}\text { Phoenixville, PA, } \\
\text { August } 23,1996\end{array}$ \\
\hline $3 b$ & $\begin{array}{l}\text { Grade crossing } \\
\text { collision with } \\
\text { highway truck } \\
\text { carrying logs }\end{array}$ & $\begin{array}{l}\text { Loading of } \\
\text { window } \\
\text { frame } \\
\text { structure }\end{array}$ & $\begin{array}{l}\text { Window } \\
\text { frame } \\
\text { structure }\end{array}$ & \\
\hline 4 & $\begin{array}{l}\text { Object, such as a } \\
\text { trailer, fouling } \\
\text { right-of-way of } \\
\text { locomotive }\end{array}$ & $\begin{array}{l}\text { Deflection; } \\
\text { corner } \\
\text { loading of } \\
\text { locomotive }\end{array}$ & Short hood & $\begin{array}{l}\text { Selma, NC, May } \\
16,1994\end{array}$ \\
\hline 5 & $\begin{array}{l}\text { Offset collision } \\
\text { between } \\
\text { locomotive and } \\
\text { freight car }\end{array}$ & $\begin{array}{l}\text { Deflection; } \\
\text { corner } \\
\text { loading of } \\
\text { locomotive }\end{array}$ & Front plate & $\begin{array}{l}\text { Madrone, NM, } \\
\text { October 13, } 1995\end{array}$ \\
\hline
\end{tabular}

Figure 2a. shows schematic illustrations for the inline collision scenarios - Scenarios 1, 2, and 3b. In Scenario 1, the principal concern is a trailing locomotive overriding the leading locomotive, consequently eliminating the operator's cab (survival space) during the collision. In scenario 2 the principal concern is the relatively strong underframe of one colliding locomotive overriding the underframe of the other locomotive. In this scenario, the overriding locomotive crushes the operator's cab of the overriden locomotive. In scenario 3, the principal concern is the destruction of the upper portion (window area) of the operator's cab.

Figure 2b. shows schematic illustrations of the oblique collision scenarios - Scenarios 4 and 5. The illustration for Scenario 4 shows an intermodal trailer fouling the right of way of an oncoming locomotive. The principal concern is with the trailer striking the short hood outboard of the collision post and consequently causing sufficient damage to intrude into the operator's cab. The illustration of Scenario 5 shows a locomotive obliquely colliding with a freight car at a switch. The principal concern is that the freight car can intrude into the operator's volume by raking down the side of the locomotive.

Scenario 1

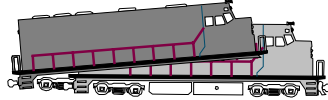

Scenario 2

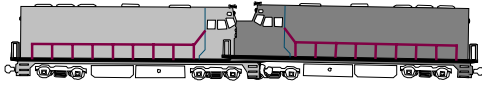

Scenario 3

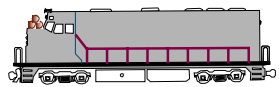

Figure 2a. Schematics of In-Line Collision Scenarios.
Scenario 4

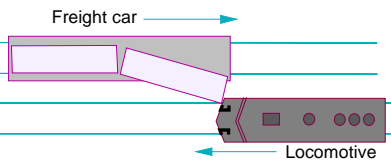

Scenario 5

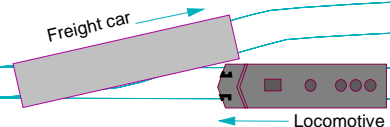

Figure 2b. Schematics of Oblique Collision Scenarios.

\section{MODIFICATION DESCRIPTIONS}

Locomotive design modifications for increased crashworthiness considered included:

- Shelf couplers: Some tank cars are equipped with couplers which have a shelf which limits vertical motion between two coupled couplers to approximately $\pm 71 / 4$ inches $(184 \mathrm{~mm})$. Passenger cars are typically equipped with tightlock couplers which keep the coupler faces at the same height. These couplers have demonstrated their effectiveness in preventing override for their respective equipment. The potential for such coupler designs in preventing locomotive to locomotive override in a head-on collision was evaluated.

- Interlocking anti-climber: The anti-climber design employed by the Canadian National was evaluated. This design incorporates thicker webs and flanges than typical North American designs, and also includes exposed flanges running the width of the anticlimber.

- Stronger collision posts: Preliminary designs of collision posts with strengths up to the strength of the main underframe structure of the locomotive were developed and evaluated. Principal modifications were the addition of flanges and tapering the collision post.

- Stronger window area structure: Increased cab strength above the short hood was evaluated. Modification included the use of thicker sheet metal for the window frame members.

- Stronger short hood: The influence of short hood strength on locomotive crashworthiness in an oblique collision was evaluated. Modifications evaluated included thickness of the short hood and the material used to make the short hood.

- Front plate: Increased front plate strength was considered as a potential modification for increased locomotive crashworthiness in an oblique collision with a freight car. The modification considered consisted of increased front plate thickness.

The structural elements considered for crashworthiness design modifications are illustrated in Figure 3.

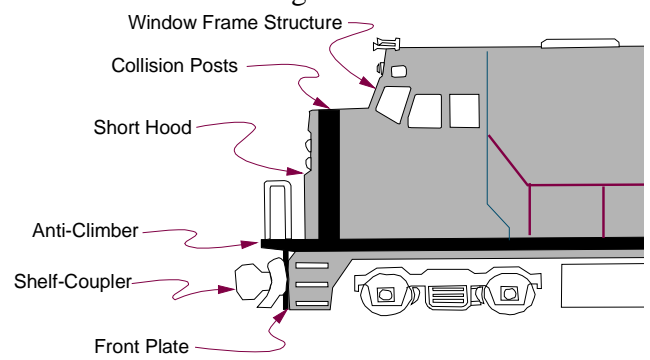

Figure 3. Schematic Drawing Showing Components Considered for Design Modification. 


\section{ANALYSES RESULTS}

\section{Scenario 1 - Coupled Locomotive Override}

The locomotive crashworthiness design modifications evaluated with this scenario include shelf couplers, such as the Association of American Railroad (AAR) Shelf-E coupler, and the CN anti-climber design. Shelf couplers are effective if the climb is owing to uncoupling of the cars, i.e., the face of one coupler sliding past the face of the other coupler (Diboll and Peters, 1980, Tong and Orringer, 1980). In order to be effective, an anti-climber must be able to provide sufficient vertical load and include a geometry that engages the anticlimber or some other structure on the opposing equipment. The $\mathrm{CN}$ anti-climber design employs significantly heavier webs and flanges than typical US anti-climber designs, and also incorporates lateral ribs along its face.

Figure 4. shows a schematic representation of the initial conditions of the head-on locomotive to locomotive collision that occurred in Smithfield, West Virginia on August 20, 1996. The closing speed for this accident was approximately $46 \mathrm{mph}(74 \mathrm{~km} / \mathrm{h})$. In this collision, a trailing locomotive overrode the lead locomotive, substantially damaging the operator's cab of the lead locomotive.

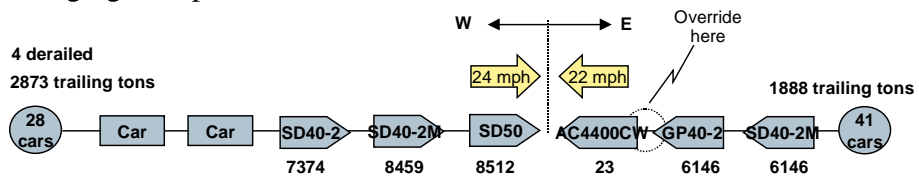

Figure 4. Head-on Collision with Coupled Locomotive Override, Smithfield, WV, August 20, 1996.

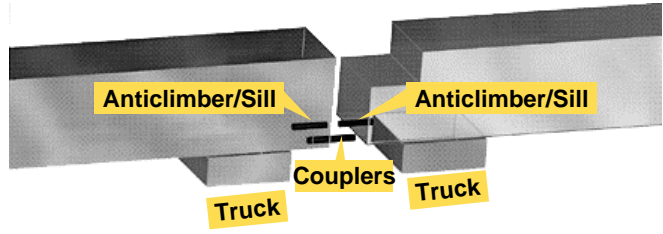

Figure 5. Head-On Collision Dynamics Model, Detail Showing Coupled Locomotives.

A detail of the collision dynamics model showing the coupler connection where the override occurred for this collision scenario is shown in Figure 5. The model includes all six of the locomotives involved in the collision. The model does not include the trailing freight cars. Owing to the weaker structures of the freight cars, they do not have a large influence on the collision of the lead locomotives (Mayville, et al, 1996). The force/crush elements in the model are derived from detailed finite-element models of the main sill and anticlimber of the locomotive, and limit-load analyses of the coupler and draft gear.

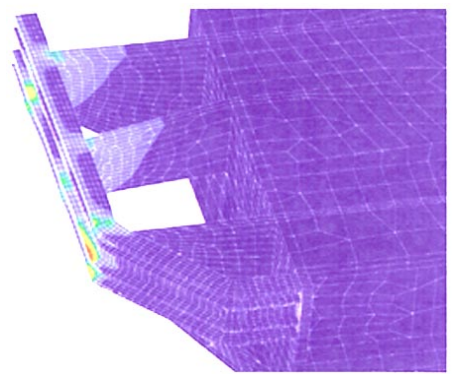

Figure 6. Anti-climber Crush Model, Top Plate Removed to Show Structural Details.
Figure 6 shows the detailed finite element model used to determine the crush behavior of the $\mathrm{CN}$ and typical US anti-climber designs. This model includes 12,000 solid and shell elements. The $\mathrm{CN}$-anti-climber design is shown in the figure, with the lateral ribs running along its face.

Figure 7. shows the peak strength of three anti-climber designs: one that just meets the requirements of the AAR S-580, a typical US design and the $\mathrm{CN}$ design. The $\mathrm{CN}$ design does provide significantly more longitudinal strength than the other two designs, however, when initially undeformed, it provides only modestly more strength in the vertical direction than the typical US design. These loads were determined by dynamically applying either a vertical or a longitudinal load to the anti-climber model until the peak force was reached, and the load began to decrease.

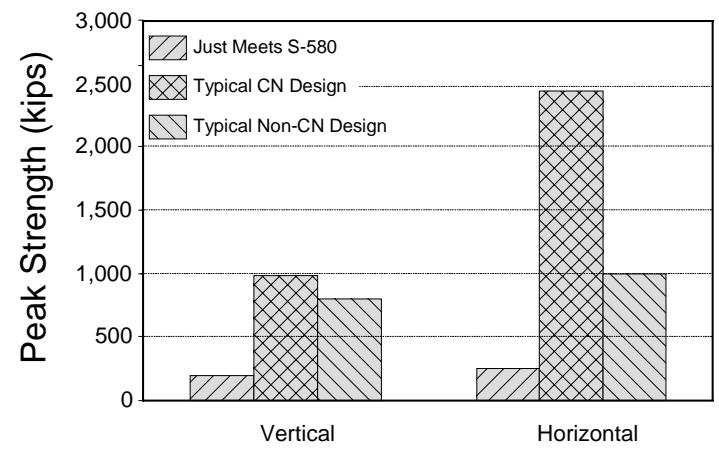

Figure 7. Peak Vertical and Longitudinal Strength, Three Initially Undeformed Anti-Climber Designs.

Figure 8. shows a case where the load was applied to the anti-climber at an upward angle of 30 degrees. The figure shows that the anticlimber loses its vertical load carrying capacity as it crushes. At about 6 inches $(152 \mathrm{~mm})$ of crush the anti-climber has approximately $1 / 2$ the vertical load capacity as at 1 inch $(25 \mathrm{~mm})$ of crush. This loss of vertical load capacity is due to the substantial fracture that occurs as the anti-climber crushes. The longitudinal crush of the anti-climber causes webs behind the face to fracture. While these fractured webs can still resist a compression load, they cannot transmit a vertical shear load.

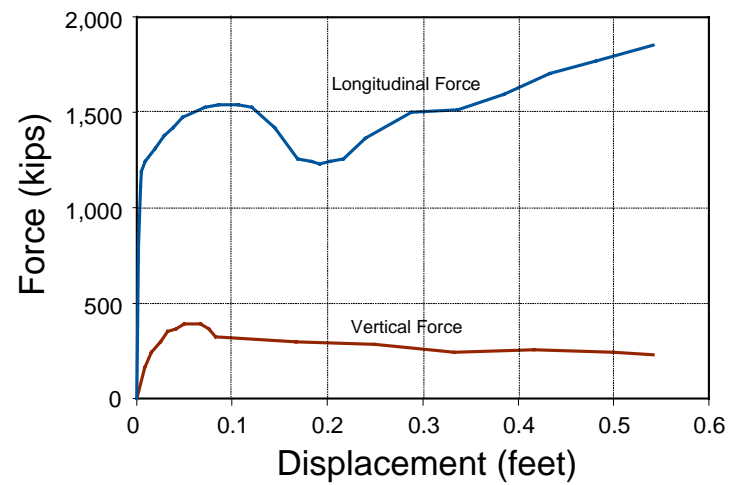

Figure 8. Longitudinal and Vertical Forces, Upward Angled Force Applied to CN Anti-Climber Design.

Figure 9. shows the predicted longitudinal forces acting on the coupler, anti-climber and main sill of the locomotive as a function of time. These results are for the Smithfield collision conditions, but with a CN-design anti-climber. The simulation shows that the $\mathrm{CN}$ - 
design anti-climber has little influence on the outcome of the collision. This is owing to the $\mathrm{CN}$ anti-climber design not having sufficient vertical load carrying capacity as it crushes longitudinally.

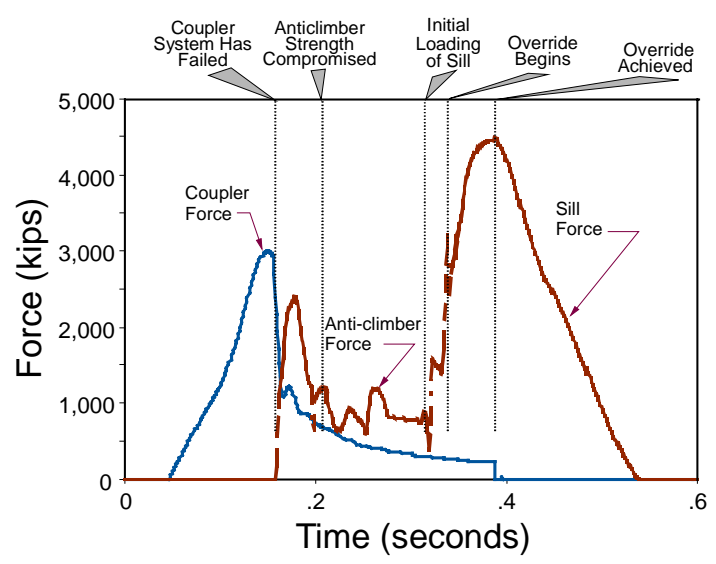

Figure 9. Coupler, Anti-Climber, and Main Sill Longitudinal Forces as a Function of Time, Simulated In-Line Collision.

The 3,000 kip (13.3 MN) longitudinal load acting on the coupler is sufficient to cause failure of the draft gear support structure. The strength of the coupler in compression and bending and the coupler carrier were evaluated with limit load analyses. Figure 10 shows the results of these analyses. The analyses indicate that for essentially the same load the coupler shank fails in bending and compression and the coupler carrier fails. Failure owing to any one of these modes can lead to override initiation. A shelf coupler will not be effective if any one of these failures occurs. The conclusion from these analyses is that shelf couplers will not be effective in preventing coupled locomotive override. (Shelf couplers are effective in preventing coupled freight car override because the main sill of the freight car will crush before the coupler will break. In addition, freight car coupler shanks are typically longer than locomotive coupler shanks, allowing greater vertical displacement of the coupler head, and hence a greater tendency for coupler heads to slide past each other before the freight car coupler shank will break in bending (Diboll and Peters, 1980, Tong and Orringer, 1980)).

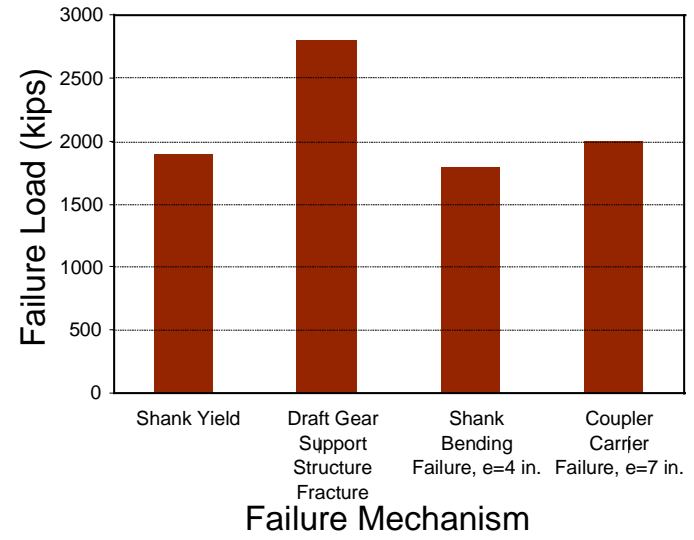

Figure 10. Failure Loads for Coupler Shank Compression and Bending, Draft Gear Support Structure, and Coupler Carrier.

The collision dynamics model was exercised to determine what vertical loads are required to prevent coupled locomotive overide. The model results indicate that a vertical load of 400 kips $(1.78 \mathrm{MN})$ must be sustained as the coupler crushes. Such an anti-climber does appear to be feasible. The anti-climber designs of Amtrak's high horsepower and High Speed Trainset locomotives are intended to crush without fracturing. This controlled crush is accomplished by using a relatively ductile material, and relatively thin but numerous webs and flanges. This design is not intended to support 400 kips $(1.78 \mathrm{MN})$ vertical load. However, it does appear possible that an anti-climber capable of supporting a $400 \mathrm{kip}(1.78 \mathrm{MN})$ vertical load could be developed using a similar design strategy. An additional requirement would be the graceful failure of the coupler and draft gear system, to prevent the formation of a ramp. Development of such an anti-climber design is beyond the scope of this study.

\section{Scenario 2 - Colliding Locomotive Override}

In this scenario, the collision mode results in loading of the collision posts. If this load is sufficient, the posts may fail, leading to substantial crush of the operator's cab. Collision post designs with strength levels up to the maximum which can be supported by the underframe were investigated.

Figure 11. shows a schematic representation of the head-on collision that occurred in West Eola, Illinois on January 20, 1993. The closing speed for this collision was approximately $30 \mathrm{mph}(48 \mathrm{~km} / \mathrm{h})$. Locomotive 7072 overrode locomotive 9710, crushing the operator's cab, as shown in the Figure 12.

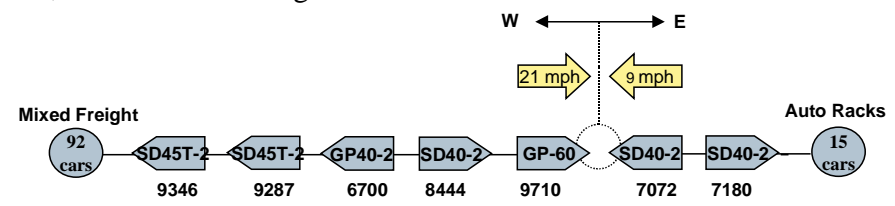

Figure 11. Head-On Collision with Colliding Locomotive Override, West Eola, Illinois, January 20, 1993.

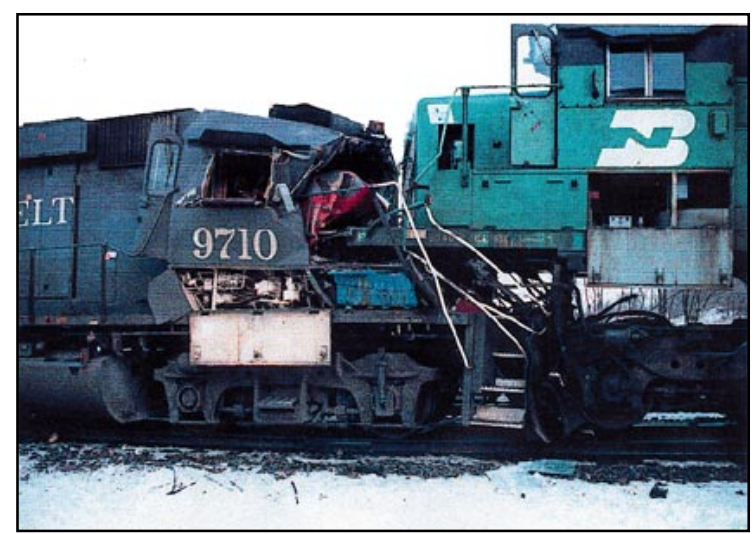

Figure 12. Post Accident Photograph, Head-On Collision, West Eola, Illinois, January 20, 1993.

A detail of the collision dynamics model at the collision interface is shown in Figure 13. The model includes all seven of the locomotives in the collision. As in the collision dynamics model for collision scenario 1 , the trailing freight cars are neglected owing to their lower strength (Mayville, et al, 1996). 


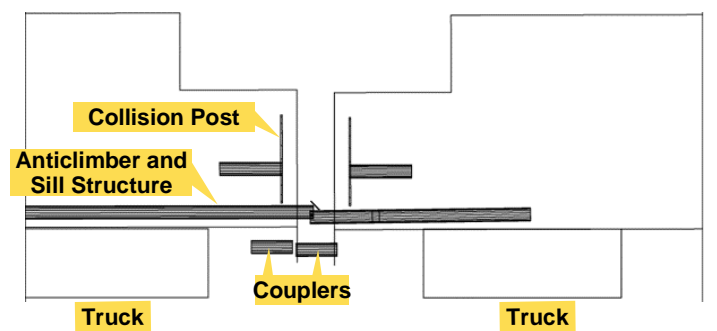

Figure 13. Scenario 2 Collision Dynamics Model, Detail Showing Colliding Locomotives.

Figure 14. shows the finite-element model used to develop the force/crush characteristic for the collision post element in the collision dynamics model. The collision post design shown is modified from the typical US design, by tapering at the top and the addition of flanges. In this model, the collision post was dynamically loaded at a point 30 inches $(762 \mathrm{~mm})$ above the deck of the locomotive.

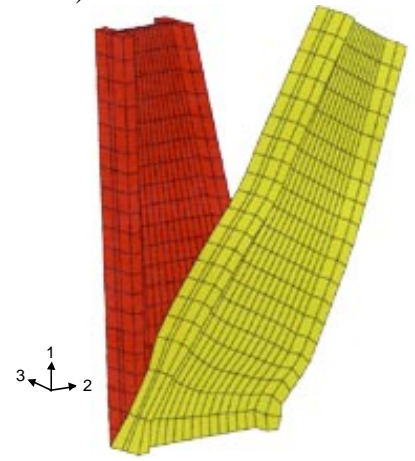

Figure 14. Collision Post Crush Model, Modified Design.

Figure 15. shows force/crush characteristics for the conventional design and two modified collision post designs, for an impactor striking the collision posts 30 inches $(762 \mathrm{~mm})$ above the subframe. Both modified designs are tapered and have flanges as shown in Figure 14. The increase in strength of the modified designs is principally owing to the addition of the flanges. The flanges allow the collision posts to maintain force level as the collision posts crush. The reduction in strength of the conventional design as it crushes is principally owing to the collision post twisting about a vertical axis and the consequent reduction in its moment of inertia about the lateral axis about which it is bending. The modified designs also twist, but at a larger crush displacement, and their moments of inertia about the lateral axis do not change as much as the conventional design.

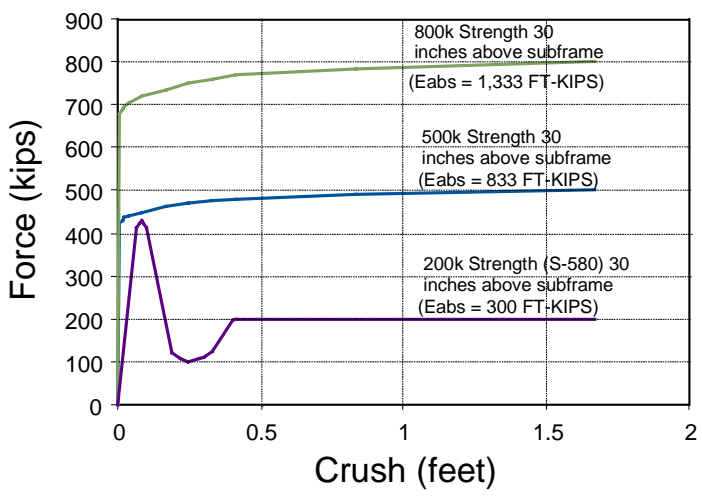

Figure 15. Collision Post Force/Crush Characteristics, Conventional and Two Modified Designs.
Figure 16. shows the maximum safe closing speed for the three different collision post designs. The 500 kip $(2.22 \mathrm{MN})$ maximum strength modified design would be just sufficient to prevent intrusion into the operator's cab at a closing speed of $30 \mathrm{mph}(48 \mathrm{~km} / \mathrm{h})$, while the 800 kip (3.56 MN) maximum strength modified design would prevent intrusion into the operator's cab at a closing speed of $37 \mathrm{mph}$ $(60 \mathrm{~km} / \mathrm{h})$.

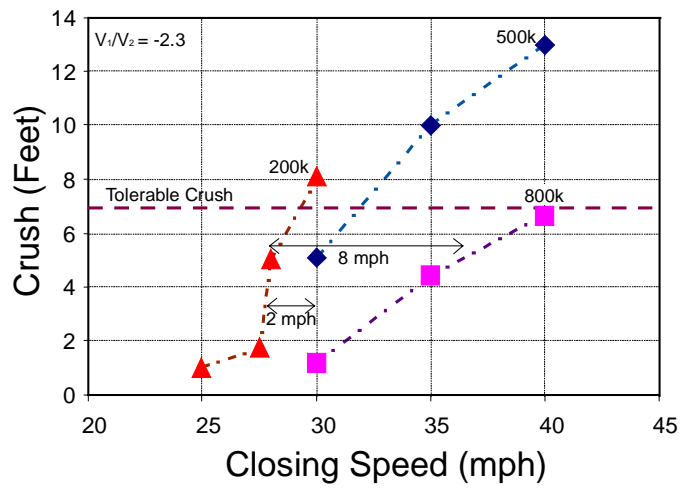

Figure 16. Scenario 2, Locomotive Crush vs. Closing Speed.

The modified design with approximately 800 kips (3.56 MN) maximum longitudinal crush force weighs the same as the conventional design. The modified design with approximately 500 kips $(2.22 \mathrm{MN})$ maximum longitudinal crush force weighs somewhat less than the conventional design.

\section{Scenarios 3a and 3b - Loading of Window Frame Structure}

In these scenarios, the window structure of the locomotive is impacted, and if the closing speed is great enough, the window structure of the cab can be sheared off. These scenarios were used to evaluate crashworthiness improvements owing to modifications to the window structure of the locomotive. The scenarios are illustrated schematically in Figure 17.

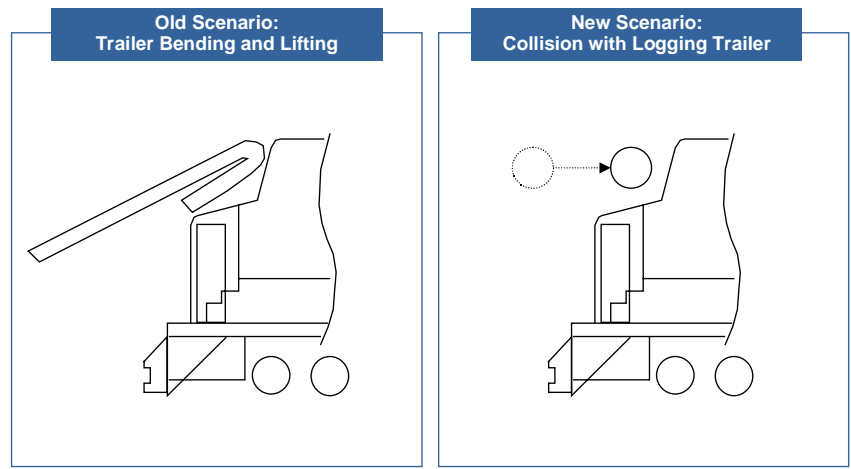

Figure 17. Schematic Drawings of Scenario 3a, Locomotive to Flat Car Overtaking Collision, and 3b, Locomotive Collision with Highway Logging Trailer.

Scenario $3 \mathrm{a}$ is based on an accident that occurred in Phoenixville, Pennsylvania on August $23^{\text {rd }}, 1996$. In that accident a locomotive-led consist travelling at approximately $32 \mathrm{mph}(51 \mathrm{~km} / \mathrm{h})$ collided with a spine (flat) car at the rear of a standing train. During the collision the spine car folded back at the body bolster, while the upper portion of the locomotive was sheared off by the impact with the bent underframe of the flat car. 
Similar to the other collision scenarios, a collision dynamics model and a crush model were developed. From the results of the analysis with the collision dynamics model, it was concluded that modifications to the strength of the window structure would have little impact on the outcome of the collision. This is owing to the large masses of the two trains and the strength of the underframe of the flat car. In order to have a significant influence on the outcome of the collision, the strength of the window structure would have to exceed the strength of the flat car underframe, which was estimated to be 1500 kips $(6.67 \mathrm{MN})$. Such strength levels were judged to be greater than could reasonably be achieved with the current freight locomotive window structure designs. Force levels that can be achieved (200 to 400 kips ( 0.89 to $1.78 \mathrm{MN}$ ) total force, side and center pillars) are only able to reduce the train speeds by a modest amount (about $2 \mathrm{mph}$ (3.2 $\mathrm{km} / \mathrm{h})$ ) in the available crush distance.

A different collision scenario with a colliding object of substantially lower mass was selected in order to determine the influence of increased window structure strength on the crashworthiness of the locomotive. In this scenario, the locomotive collides with a highway truck transporting logs. One or more logs ride up and over the short hood and impacts the locomotive cab at the window frame. The impact of concern is that of the $\log (\mathrm{s})$ with the window frame, not the impact of the underframe of the locomotive with the trailer of the highway truck. This collision scenario occurs in line, and was analyzed only with the crush model, owing to the relatively light mass of the impacting object. The crush model is shown in Figure 18. Modifications to the structure in the darkened area were evaluated with this model. The log was assumed to be rigid compared with the window structure.

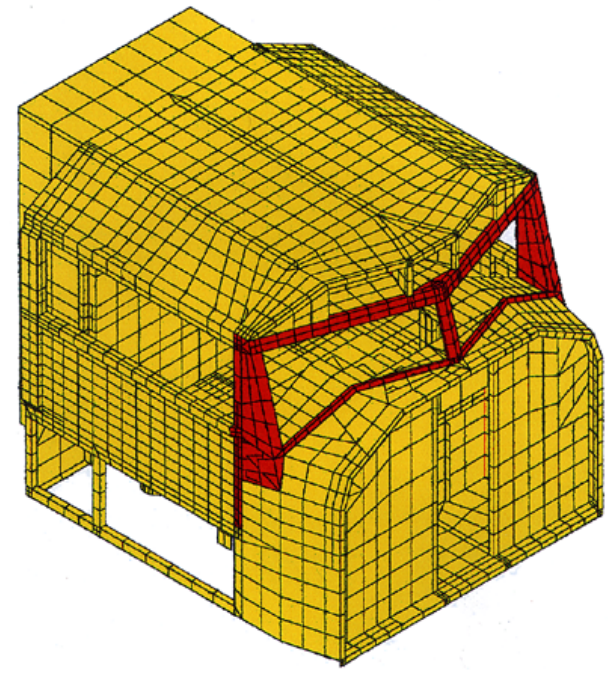

Figure 18. Collision Scenarios 3a and 3b Crush Model.

Figure 19. shows the undeformed and deformed finite element analysis mesh. The structure essentially traps the log during the collision. In a survivable collision, the deformations of the structure consists principally of bending and crushing, with very little fracture. The maximum amount of longitudinal crush of the center pillar was taken to be $21 / 2$ feet $(0.76 \mathrm{~m})$. This amount of crush brings the leading edge of the log approximately to the initial location of the rear face of the outboard window pillars.

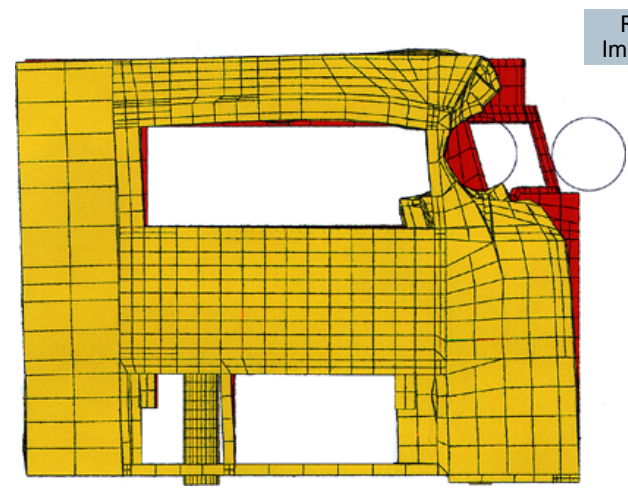

Figure 19. Deformed and Undeformed Finite Element Model Meshes, Scenario $3 b$.

Figure 20. shows the force/crush characteristics for the typical locomotive window structure design and the modified window structure design. The modification consists simply of doubling the thickness of the material. Locomotive window structures are typically constructed of formed sheet metal, and the window pillars are essentially closed, hollow section tubes. The figure also illustrates the maximum crush distance that would occur for 1, 2, and $3 \operatorname{logs}$ impacting the window structure at $50 \mathrm{mph}(80 \mathrm{~km} / \mathrm{h})$. For three logs, the modified design would be expected to have a maximum of 18 inches $(457 \mathrm{~mm})$ of crush, while the typical design is expected to have 28 inches of crush $(711 \mathrm{~mm})$.

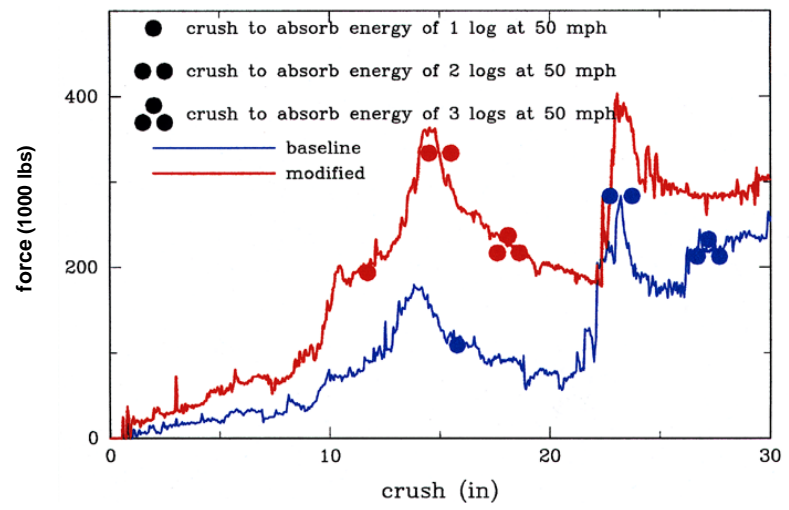

Figure 20. Force vs. Crush, Locomotive Window Structure.

Figure 21. shows the maximum window crush as a function of closing speed for an impact of three logs into the window structure. For this collision, the modified collision scenario results in an increase of 20 mph $(32 \mathrm{~km} / \mathrm{h})$ in the maximum safe closing speed over the typical US design. 


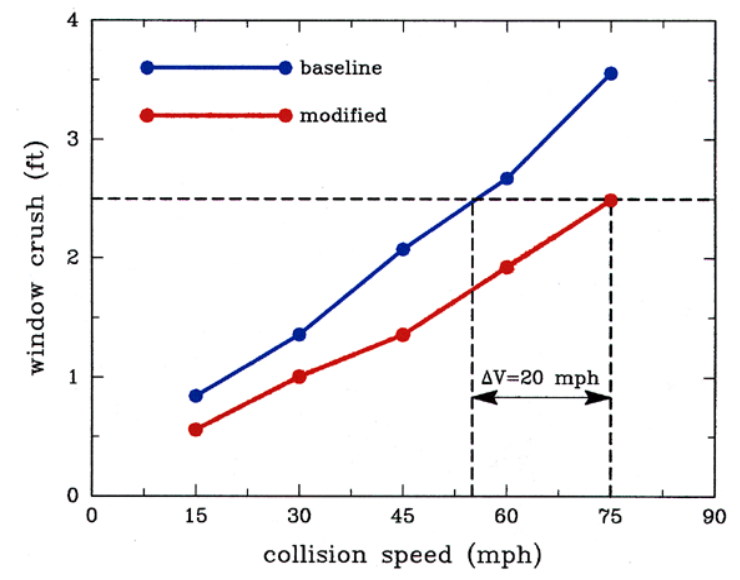

Figure 21. Window Crush vs. Closing Speed, Three Logs Impacting Locomotive Window Structure.

\section{Scenario 4 - Corner Loading of Locomotive}

On May 16, 1994 in Selma, North Carolina, a collision occurred when an overhanging intermodal trailer on the northbound CSXT 176 freight train was obstructing the right of way of the southbound Amtrak passenger train 87 . The northbound freight train was traveling approximately $35 \mathrm{mph}(56 \mathrm{~km} / \mathrm{h})$ and the southbound passenger train was traveling about $70 \mathrm{mph}(113 \mathrm{~km} / \mathrm{h})$. The forward most intermodal trailer on the fifty first car that was overhanging and engaged the lead locomotive of the passenger train. Figure 22 schematically depicts the initial conditions of the oblique collision.

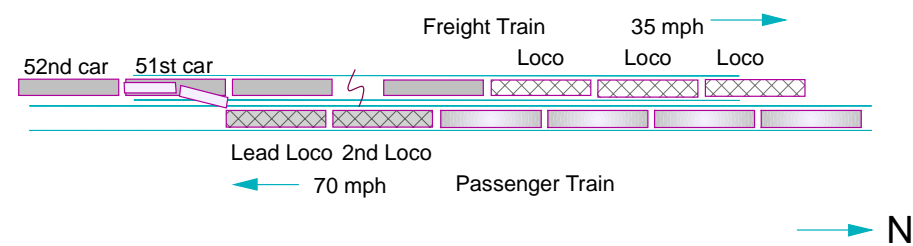

Figure 22. Oblique Collision with Intermodal Trailer, Selma, North Carolina, May 15, 1994.

A detailed finite-element model was developed to characterize the force/crush behavior of the short hood, while a three-dimensional lumped-mass collision dynamics model was developed to determine the trajectories of the locomotive and the inter-modal trailer. A crush element was used in the collision dynamics model, with the parameters for this element taken from the results of the short hood finite-element analysis. The collision dynamics analysis includes the influence of the locomotive suspension and the trailing locomotive. The model was used to evaluate the influence of short hood design on intrusion into the operator's cab, the deceleration of the locomotive during the collision, and whether derailment of the locomotive occurs owing to the collision. A schematic of the collision dynamics model is shown in Figure 23. This model is an extension to three dimensions of the two dimensional collision dynamics model described in Tyrell, at al, 1997.

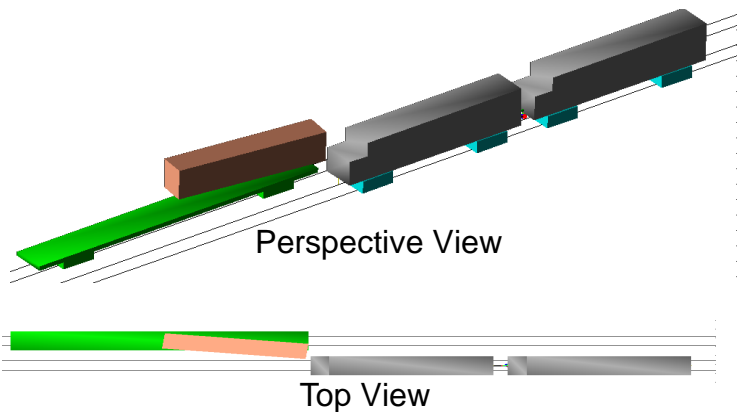

Figure 23. Oblique Collision with Intermodal Trailer, Collision Dynamics Model.

The wide nose short hood and the impacting object used in the finite element model are depicted in Figure 24. The finite element model was constructed from 5960 4-noded shell elements. The full short hood was modeled including the pair of collision posts, but the attachment to the sub-base was modeled as a fixed boundary condition. During the impact event, the hood crushes in a mode similar to an accordion. Double-sided contact is calculated to model the selfcontact between folds. The intruding object is a rigid body representing an intermodal trailer.

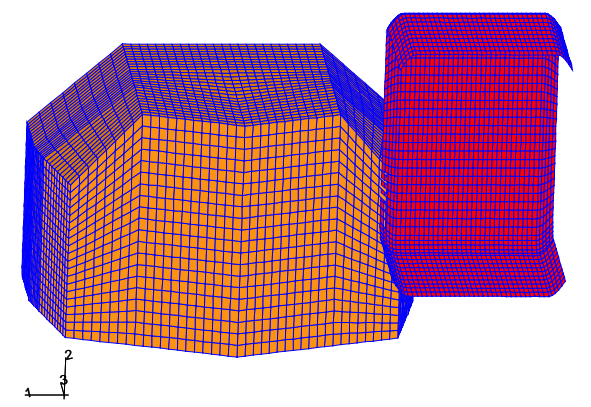

Figure 24. Short Hood Crush Model.

Figure 25 depicts a typical force/crush curve obtained using the short hood crush model. This force/crush characteristic is for a short hood design with $1 / 2$ inch $(12.7 \mathrm{~mm})$ top, side, and front plate thickness and made from $36 \mathrm{ksi}$ (248 MPa) yield strength steel. To determine an average crush force for a given crush distance, a running average was taken out to 40 inches $(1 \mathrm{~m})$ of crush.

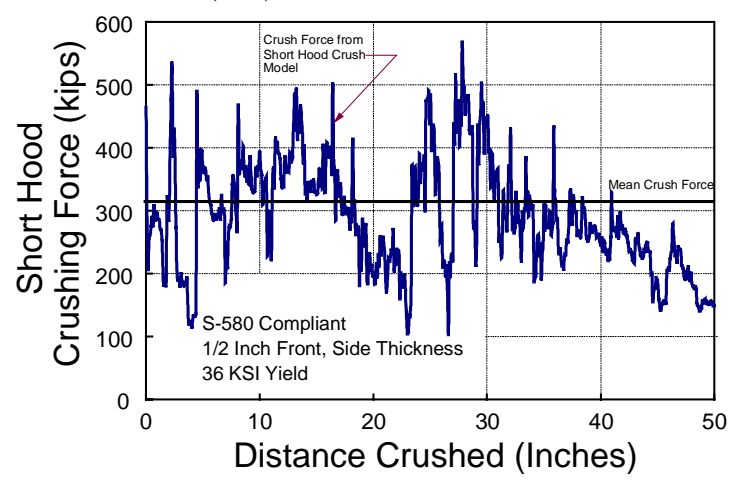

Figure 25. Short Hood Force/Crush Characteristic, $1 / 2$ inch (12.7 mm) Top, Front, and Side Thickness, 36 ksi (248 MPa) Yield Strength Material. 
Since the AAR S-580 short hood requirement can be satisfied in a variety of design configurations, force/crush behaviors of three short hood designs were evaluated with the model. Design A has uniform front, side, and top sheet metal thickness. Design B has uniform $1 / 4$ inch $(6.4 \mathrm{~mm})$ front and side thickness with $27 \mathrm{ksi}(186 \mathrm{MPa})$ yield sheet metal. Design $\mathrm{C}$ has uniform $3 / 16$ inch $(4.8 \mathrm{~mm})$ top and side thickness with $27 \mathrm{ksi}(186 \mathrm{MPa})$ yield sheet metal. The thickness of the front, side and top were varied for Design A, the front and side for the Design B, and the front only for Design C. These thicknesses were varied according to the AAR S-580 requirement for the thickness of the front sheet metal of the short hood to vary inversely with the square root of the yield strength. Table 2. lists the yield strength and corresponding S-580 thickness. Figure 26 shows the mean crush force for the three designs for the four material/thickness cases.

Table 2. Short Hood Case Number, Yield Strength, and S-580 Thickness.

\begin{tabular}{|c|c|c|c|}
\hline Case Number & $\begin{array}{c}\text { Yield } \\
\text { Strength }(\mathrm{ksi})\end{array}$ & $\begin{array}{c}\text { Ultimate } \\
\text { Strength }(\mathrm{ksi})\end{array}$ & $\begin{array}{c}\text { Thickness } \\
\text { (inches) }\end{array}$ \\
\hline 1 & 25 & 45 & $1 / 2$ \\
\hline 2 & 36 & 50 & $1 / 2$ \\
\hline 3 & 50 & 70 & $3 / 8$ \\
\hline 4 & 100 & 120 & $1 / 4$ \\
\hline
\end{tabular}

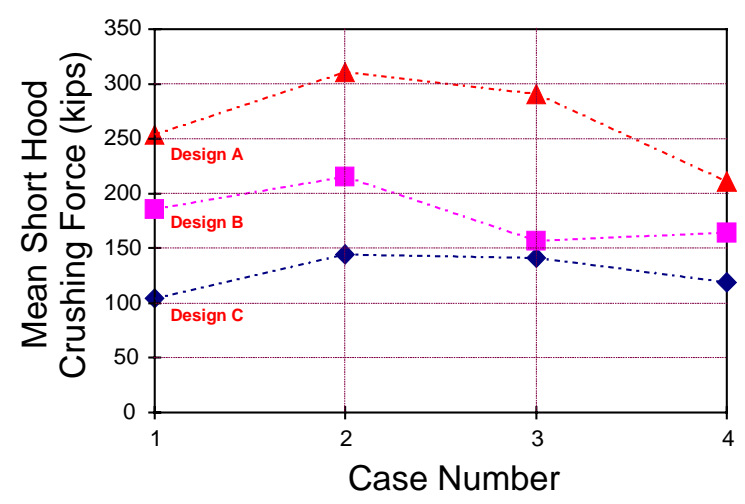

Figure 26. Short Hood Mean Crushing Force, Three Short Hood Designs.

Figure 27 shows the maximum safe closing speed for the oblique collision with an intermodal trailer. The maximum safe speed is defined as the speed which will cause a total of 5 feet $(1.5 \mathrm{~m})$ of crush. Crush greater than 5 feet $(1.5 \mathrm{~m})$ implies intrusion into the operator's cab. The 'Baseline' point in the figure corresponds with Design B, Case 1. The 'Baseline' is representative of short hood designs in current service. The maximum safe crush for this baseline design occurs at a closing speed of $56 \mathrm{mph}(90 \mathrm{~km} / \mathrm{h})$. A short hood design with uniform $3 / 4$ inch $(19 \mathrm{~mm})$ front, side, and top thickness and $25 \mathrm{ksi}$ (172 MPa) yield material was chosen as a potential modification. The maximum safe crush for this modified design occurs at a closing speed of $95 \mathrm{mph}(153 \mathrm{~km} / \mathrm{h})$, an increase of nearly $40 \mathrm{mph}(64 \mathrm{~km} / \mathrm{h})$ over the baseline. The results indicate that increased short hood strength increases the crashworthiness in this collision scenario.

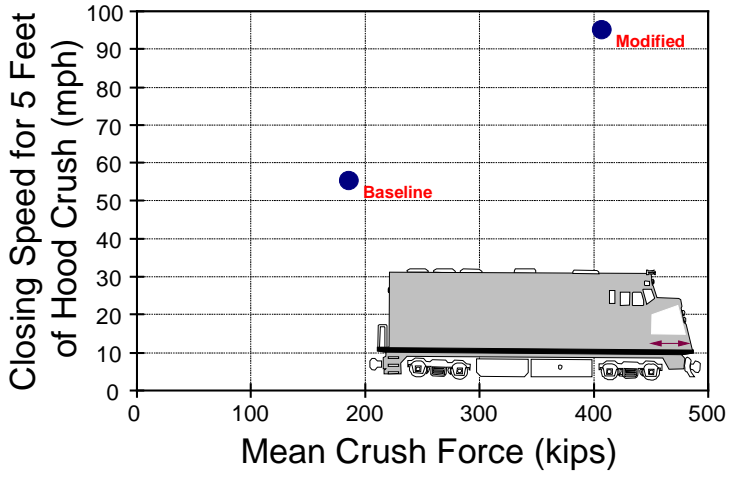

Figure 27. Maximum Safe Closing Speed vs. Short Hood Mean Crush Force, Oblique Collision with Intermodal Trailer.

\section{Scenario 5 - Corner Loading of Locomotive}

Figure 28 shows a schematic drawing of the initial conditions of the accident that occurred in Madrone, New Mexico on October 13, 1995. In this collision, a westbound locomotive-led train travelling at approximately $20 \mathrm{mph}(32 \mathrm{~km} / \mathrm{h})$ collided with the cars of an eastbound train travelling at approximately $22 \mathrm{mph}(35 \mathrm{~km} / \mathrm{h})$ as it went through a switch. Additional impacts likely occurred between the rear of the westbound lead locomotive and another freight car and the front of the second locomotive with yet another freight car. Nine freight cars had impact damage after the collision.

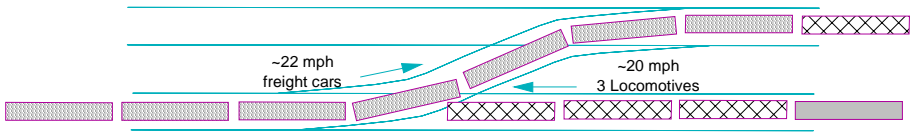

Figure 28. Scenario 5, Oblique Collision Locomotive Led Train with Cars of Another Train Traversing Switch, Madrone, New Mexico, October 13, 1995.

Figure 29 shows the impact damage to the lead locomotive and the first freight car hit. During the collision, the right half of the plow and the lower right corner of the front plate of the locomotive were sheared off. There was relatively minor damage to the short hood, which retained its general shape but had several access doors torn off. The body bolster of the covered hopper car remained essentially intact, although there is a relatively large dent in the side of the hopper car. (This car and most of the cars hit were empty at the time of the collision.)
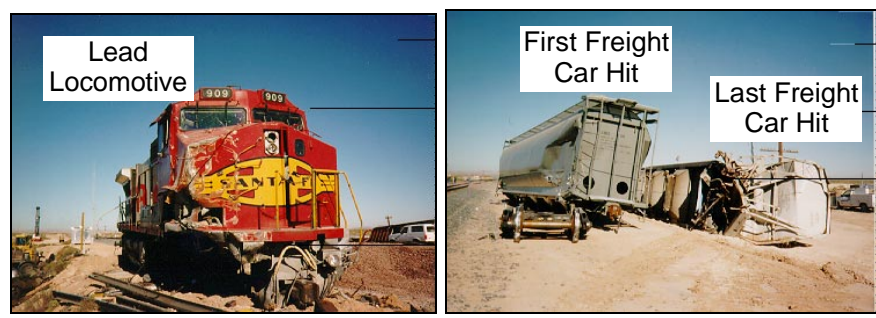

Figure 29. Post Accident Photographs, Lead Locomotive of Westbound Train and First and Last Impacted Freight Cars of Eastbound Train.

The damage to the equipment and the likely initial conditions of the first impact indicate that the loads acting between the locomotive and 
the freight car were governed by the load required to damage the plow and front plate of the locomotive and the body of the covered hopper car. Figure 30. illustrates the likely initial conditions of the first impact. The relevant structural members of the hopper car and locomotive are shown.

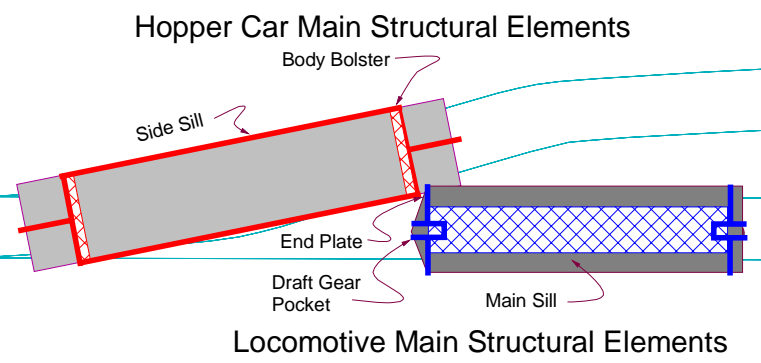

Figure 30. Scenario 5, Oblique Collision of Locomotive and Freight Car, Likely Initial Conditions of First Impact.

Modifications to the short hood are not likely to have an influence on the outcome of this collision. The net force between the short hood and the freight car body cannot exceed the force required to damage the freight car body. The existing short hood design is already sufficiently strong to damage this type of covered hopper carbody when empty. (It should be noted that the short hood may not be stronger than the body of the covered hopper if it were loaded and the short hood may not be stronger than another type of freight car body.)

While modifications to the plow and end plate may have some influence on the outcome of this collision, it is not likely that increased plow and end plate strength would improve the crashworthiness of the locomotive.

\section{SUMMARY OF CONCLUSIONS AND RECOMMENDATIONS}

The results of the study indicate that strengthened window structures, collision posts, and short hoods all result in increased crashworthiness for particular collision scenarios. Shelf couplers were found not to be effective in preventing coupled locomotive override. (Shelf couplers are potentially effective in preventing freight car override of a locomotive, however, this scenario was not evaluated.) Owing to the fracture that occurs as the $\mathrm{CN}$ anti-climber design longitudinally crushes, this design was found to be ineffective in supporting the vertical forces that occur during locomotive to locomotive override, consequently allowing such overrides to occur. The design requirements for an effective anti-climber design were developed: the principal requirement is the ability to support a 400 kip vertical load during crushing. For an oblique collision of a locomotive with an empty hopper car, modifications to the short hood are not likely to influence the outcome of the collision.

Follow-on research efforts planned include development of an engineering model design of an anti-climber arrangement which meets the design requirements developed as part of this study, and testing of short hood structures to verify the force/crush behavior and to verify the development of the direction of the forces in oblique collisions of a locomotive with an intermodal trailer.

\section{ACKNOWLEDGEMENTS}

The authors would like to thank Michael Lorenzen, Manager, Structural Analysis Group, General Motors Electromotive Division (GM/EMD) and Al Bieber, Senior Engineer, Mechanical Design,
General Electric Transportation Systems (GETS) for information on the structural design of locomotives, as well as their helpful discussions on considerations in designing locomotive structures. The authors would also like to thank John Punwani, Program Manager, Equipment and Operating Practices Division, Office of Research and Development, Federal Railroad Administration for his efforts in coordinating activities with the Association of American Railroads, the Railway Progress Institute, the United Transportation Union, and the Brotherhood of Locomotive Engineers, and Claire Orth, Chief Equipment and Operating Practices Division, Office of Research and Development, Federal Railroad Administration for her support, as well as Richard Down, Jr., Accident Investigator, National Transportation Safety Board, for the many helpful discussions on train accidents.

\section{REFERENCES}

ABAQUS/Explicit Users Manual, 1998, Hibbitt, Karlsson and Sorenson, Inc.

Bertorelli, N., Gugliotta, A., Montanini, R., Vadori, R., Structural Crash Analysis with ADAMS: A Comparison Between Multibody and FEM Approaches, $12^{\text {th }}$ European ADAMS Users' Conference, Mechanical Dynamics, Inc.

Diboll, W.B., Peters, D.A., Coupler Override Mechanisms, 1980, American Society of Mechanical Engineers.

Mayville, R., Stringfellow, R., Rancatore, R., Hosmer, T., 1996, Locomotive Crashworthiness Research - Volumes 1 to 5, DOT/FRA/ORD-95/08.1 through 08.5, Federal Railroad Administration, US Department of Transportation.

Mayville, R., Stringfellow, R., Rancatore, Johnson, K., 1999, Development of a Passenger Rail Vehicle Crush Zone, Institute of Electrical and Electronics Engineers/American Society of Mechanical Engineers Joint Railroad Conference.

Mayville, R., Rancatore, R., Tegler, L., 1999, Investigation and Simulation of Lateral Buckling in Trains, Institute of Electrical and Electronics Engineers/American Society of Mechanical Engineers Joint Railroad Conference.

Tong, P., Orringer, O., 1980, Results and Analysis of the Switchyard Impact Tests, DOT/FRA/ORD-80-6, Federal Railroad Administration, US Department of Transportation.

Tyrell, D., Severson, K., Mayville, R., Stringfellow, R., Berry, S., Perlman, A.B., 1997, Evaluation of Cab Car Crashworthiness Design Modifications, Institute of Electrical and Electronics Engineers, Cat. No. 97CH36047, pp 49-58. 